\title{
The Gulf of Carpentaria was a heat source to Torres Strait and the Northern Great Barrier Reef during the 2016 mass coral bleaching event
}

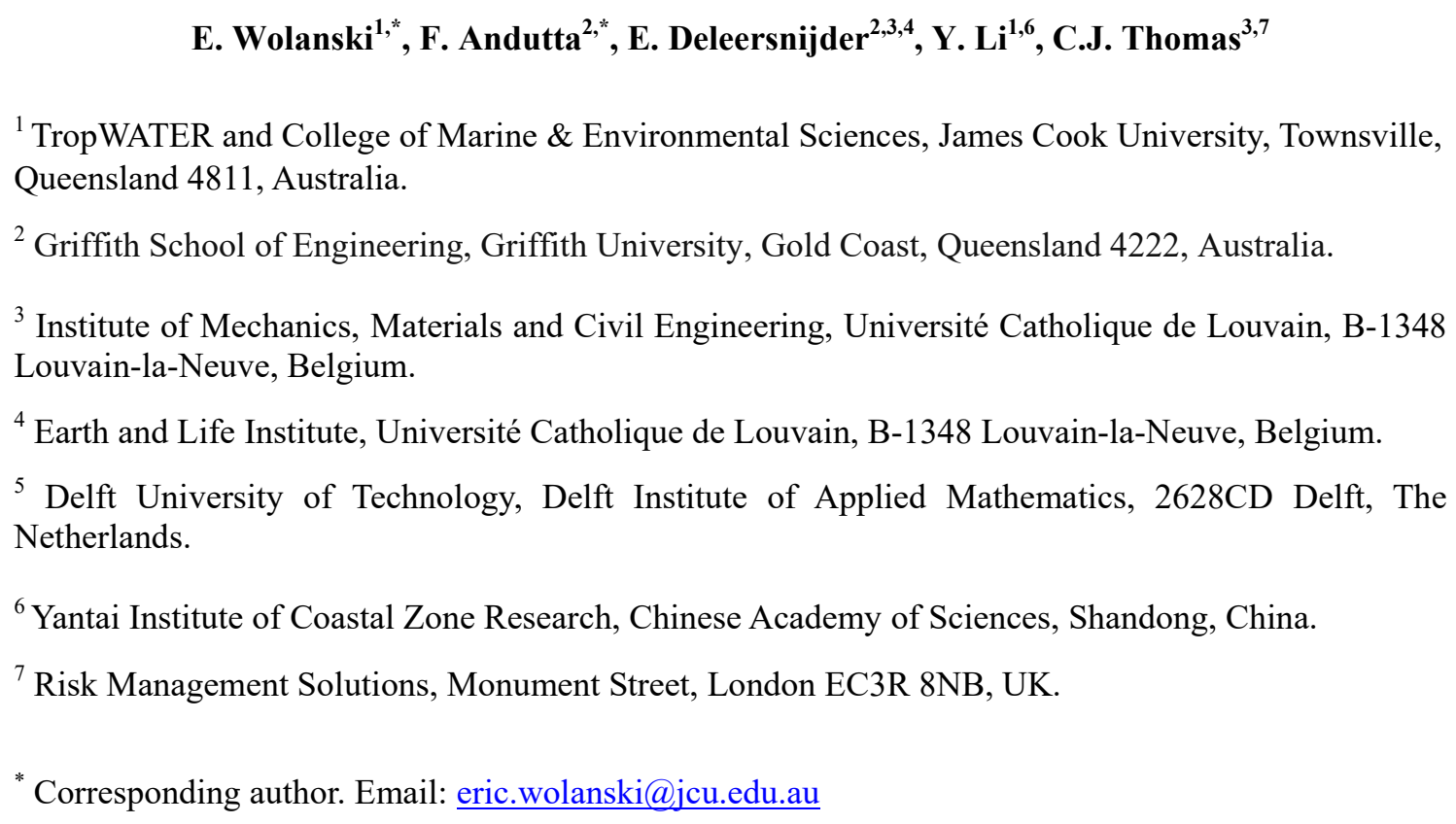




\section{Key Points:}

23

24- The heat stress on Torres Strait and the Northern Great Barrier Reef was mapped bi-monthly.

25• The Gulf of Carpentaria was an important heat source to Torres Strait and the Northern Great Barrier

26 Reef, in addition to local heating.

27• The North Queensland Coastal Current ceased, inhibiting flushing and cooling of the Northern Great

28 Barrier Reef.

29• Coral bleaching was the largest where heat was trapped in the least flushed waters.

30

31 


\section{Abstract}

33 The 2015/16 ENSO event severely raised the temperature of waters surrounding northeast Australia to 34 above $30{ }^{\circ} \mathrm{C}$, with large patches of water reaching $32{ }^{\circ} \mathrm{C}$, for over two months, which lead to severe 35 bleaching of coral reefs of the Northern Great Barrier Reef (NGBR). This study provides evidence 36 through remote-sensing data and oceanographic modeling that three factors caused this excessive 37 heating, namely: 1) the shutdown of the North Queensland Coastal Current, which would otherwise 38 have flushed and cooled the Northern Coral Sea and also the NGBR through tidal flushing, 2) the 39 advection of warm $\left(>30^{\circ} \mathrm{C}\right)$ water from the Gulf of Carpentaria eastward through Torres Strait and 40 then southward over the NGBR continental shelf, and 3) local solar heating. The eastward flux of this 41 warm water through Torres Strait was driven by a through-strait mean sea level difference that in turn 42 was controlled by the wind, and the wind also generated the southward advection of this warm water onto the NGBR shelf. On the NGBR shelf, the residence time of this warm water was larger inshore 44 than offshore, and this may explain the observed cross-shelf gradient of coral bleaching intensity.

46 Keywords: Water circulation; heat advection; trapping; stagnation; coral bleaching 
50 Coral reefs worldwide and in the Great Barrier Reef (GBR) in particular are increasingly degraded by 51 the cumulative impacts of a number of stressors [Douglas, 2003; Hoegh-Guldberg et al., 2007; Brodie 52 and Waterhouse, 2012; Ainsworth et al., 2016]. These include pollution from terrestrial runoff [Brodie 53 et al., 2012; Fabricius et al., 2016; McCulloch et al., 2003], overfishing [Jackson et al., 2001], 54 predation by crown-of-thorns starfish [Brodie et al., 2005; Fabricius et al., 2010], ocean acidification 55 [Fabricius et al., 2011; Mongin et al., 2016; Golbuu et al., 2016] and increased heat stress [Brown, 56 1997; Manzello, 2015] that may also promote coral-disease outbreaks and mortality [Precht et al., 57 2016]. Among these stressors, heat stress is the main cause of coral bleaching [Douglas, 2003]. 58 It was long assumed that Torres Strait (TS) and the northern GBR (NGBR, Figure 1) was the least likely region of the GBR to be impacted by these stressors because until early 2016 it was 60 healthy and presumed resilient, and because the human impacts from land-use and overfishing have 61 been minimal in that region [Brodie and Pearson, 2016]. Thus the extensive coral bleaching in Torres 62 Strait and the NGBR during the 2016 austral summer ENSO event (http://www.gbrmpa.gov.au/media63 room/coral-bleaching) was an unwelcome surprise. In this paper, we propose an oceanographic explanation for what happened. No descriptive analysis of the physical oceanographic aspects of this mass coral bleaching event has been carried out so far. Filling this gap is the objective of the present study. We first describe the domain and we summarise what is known of the oceanography of the

67 Northern Coral Sea (NCS), TS and the NGBR. We review the oceanographic, meteorologic and satellite-derived mean sea level and sea surface temperature data for that ENSO event in this area and the surrounding waters of the northern Coral Sea, the Gulf of Papua (GP) and the Gulf of Carpentaria

70 (GC). We then use oceanographic models to explain and synthesize these observations. This paper

71 thus reveals the likely sequence of events that led to warm $\left(>30{ }^{\circ} \mathrm{C}\right.$, peaking at $\left.32{ }^{\circ} \mathrm{C}\right)$ water

72 temperatures over the reefs of NGBR and TS, thereby causing a mass coral bleaching. We also suggest that the spatial variation of residence time of this very warm water over the NGBR shelf explains the observed spatial pattern of coral bleaching. 


\section{Site description}

The NGBR (Figure 1) is a lagoon that has limited water exchange with the NCS through a series of narrow reef passages between long reefs that block $\sim 80 \%$ of the length of the shelf break [Pickard et al., 1977]. Therefore, the NGBR water circulation differs from that in the adjoining central GBR region where reefs block only $\sim 10 \%$ of the shelf break length and where as a result the South Equatorial Current in the Coral Sea intrudes on the GBR shelf [Wolanski, 1994; Andutta et al., 2013 ]. In the NGBR, the water depth is $\sim 10 \mathrm{~m}$ on the inner shelf, $\sim 30-40 \mathrm{~m}$ on the outer shelf, and $<3 \mathrm{~m}$ over most reefs (Figure 1). The NGBR has three open boundaries, namely the reef passages linking it with the NCS, the southern boundary across the shelf linking it with the central GBR, and the northern boundary linking it with TS. This southern boundary is largely closed due to a high density of reefs leaving open only a narrow passage (see the arrow in Figure 1c). The net currents over the NGBR are wind-driven, with no evidence of the North Queensland Coastal Current (NQCC), which flows northward offshore from the continental shelf, intruding on the shelf; thus the net currents vanish during calm weather conditions [Wolanski and Ruddick, 1981; Wolanski and Thomson, 1984; Cahill and Middleton, 1993]. These net currents are strongly modulated by tidal friction; thus the local tidal currents modulate the net water circulation over the NGBR and the TS [Wolanski and Thomson, 1984].

The TS (Figure 1) connects the Gulf of Carpentaria (GC) to the Gulf of Papua (GP), the NGBR and the NCS. The bathymetry is extremely complex with numerous islands, reefs, reef passages and shoals. To the west, i.e. on the GC side of TS, the water depth is $\sim 10-20 \mathrm{~m}$. In most of TS the depth varies between 5 and $20 \mathrm{~m}$ (Figure 1). Along the eastern boundary of TS, just like on the NGBR, the reefs occupy $\sim 80 \%$ of the distance along the shelf break [Pickard et al., 1977]. A small, net throughflow occurs through these open boundaries driven by the wind and the mean sea level (MSL) difference across TS [Wolanski et al., 2013].

The NCS is deep (depth can exceed $4000 \mathrm{~m}$ ) and the surface mixed layer is typically $100 \mathrm{~m}$ thick. The net circulation in that layer is driven by the NQCC flowing northward offshore from the 
104 NGBR, then veering eastward to flow along the south coast of Papua New Guinea but not intruding 105 over the shallow Gulf of Papua (GP) [Andrews and Clegg, 1989; Wolanski et al., 1995; Wolanski et 106 al., 2013; Kessler and Cravatte, 2013]. The NQCC thus brings cooler (from higher latitudes) water to 107 the tropical NCS.

\section{Methods}

Sea surface temperature (SST) and cloud coverage

Maps of SST were obtained from satellite data based on AVHRR instruments (IMOS, 2016) over the period of 15 Nov 2015 to 1 May 2016. SSTs were extracted on a 2D grid covering the entire NGBR region with a cell size of $0.02^{\circ} \times 0.02^{\circ}$, with each cell representing SST averaged over 14 days. SSTs are representative of a depth of $\sim 1$ metre. Whilst the data coverage was limited during certain time periods, overall they provided a relatively complete picture during the time window analysed. We also analysed the 3-day averaged SST data to see if they revealed any additional insights into the dynamics of the warming event; however there was no apparent improvement because of the patchiness of the data due to cloud coverage. Thus we only present the 14-day averaged data here as these were felt to best show the evolution of the warming event. Finally, we also examined the cloud images from November 2015 to April 2016 from the Australian Bureau of Meteorology and from the NOAA VIIRS imagery dataset; visually we could not spot any areas with significantly more clouds than the rest, though the data were very patchy in time and space. Altimetry data

The altimeter MSL data for TS were produced by Ssalto / Duacs and distributed by Aviso, with support from CNES (http://www.aviso.altimetry.fr/). The horizontal resolution was $0.25^{\circ}$. These weekly data were used to calculate the difference in the MSL across TS.

127 Altimetry-derived surface currents in the NCS were obtained from NOAA OSCAR. The spatial and 128 temporal resolution of the data was $1 / 3^{\circ}$ and 5 days respectively, from mid-November 2015 to mid129 April 2016. 
The 3-hourly wind data at Coconut Island (a flat island just a few metres above sea level and located

$132130 \mathrm{~km}$ north-east of Cape York, in the southern TS) were obtained from the Australian Bureau of Meteorology. The only other wind data available in TS were those from Horn Island, next to Cape York, but these data were not used in this study because they were aliased by orographic effects.

The drift trajectories in the NCS of warm water plumes originating from the outer GBR was calculated using the method of Oliveira and Stratoudakis (2008) and Wolanski (2016); namely a 2D oceanographic advection-diffusion model was used whereby the advection model was providing to the dispersion model the observed surface currents measured by satellite altimetry. The seeding points were chosen at regular intervals along the western boundary of the NCS fringing the NGBR. A total of 100,000 virtual particles were released in mid-late November 2015. We assumed that the value of the horizontal eddy diffusion coefficient $\mathrm{K}_{\mathrm{x}}$ was $10 \mathrm{~m}^{2} \mathrm{~s}^{-1}$.

\section{TS and NGBR oceanographic modelling}

145

146 We could not use altimetry in TS and the NGBR because the waters are shallow and the currents are strongly influenced by friction and the bathymetry. For TS and the NGBR we used the SLIM model. This model is a free-surface, hydrostatic, depth-averaged, primitive equation ocean model that uses am unstructured mesh. SLIM has already been successfully used to model the circulation in the GBR and TS [Legrand et al., 2006; Lambrechts et al., 2008; Andutta et al., 2012, 2013; Wolanski et al., 2013]. Using an unstructured mesh allows the spatial resolution to be made locally higher in shallow areas and near coastlines, where small-scale flow features are important, and lower in deeper areas, where the flow is more uniform. This approach allows the model to resolve a wide range of scales of motion, from regional flows to eddies behind reefs and islands and tidal jets that develop between reefs and islands, as well as intermediate-scale effects such as the sticky waters effect in a dense reef 
mosaic [Hughes et al., 2008; Andutta et al., 2012]. The model domains and the model mesh for TS and NGBR are shown in Figure 1. The TS model forcing follows Wolanski et al. (2013), i.e. it was forced by the tides, the wind at Coconut Island, the MSL data from altimetry, and, along the southern open boundaries, the tidal and the net currents. The tidal currents were taken from Wolanski et al. (2013). According to the historical field measurements of Wolanski and Ruddick (1981), Wolanski and Thomson (1984) and Cahill and Middleton (1993) for the NGBR and from Wolanski (1993) for the $\mathrm{GC}$, the net currents were proportional to the wind and vanished in calm weather conditions. The coefficient of proportionality between winds and net currents was derived from these historical field data. Forcing by wave breaking on the reef crest at the shelf break was assumed to be negligible because (see later) the dominant wind was seaward and wind waves and swell are negligible in this area under such wind conditions in the absence of storms or cyclones elsewhere in the Coral Sea (EW, unpublished). The NGBR model was similarly forced by the wind, the tides in the NCS, and the tidal and net currents over the southern and northern open boundaries over the NGBR shelf. To follow the trajectories of warm water plumes, we released particles at a number of points and we assumed $\mathrm{K}_{\mathrm{x}}=$ $10 \mathrm{~m}^{2} \mathrm{~s}^{-1}$. River discharges were negligible, and thus not included in the simulations.

\section{Results}

Figure 2 shows sequential plots of the distribution of SST in the NGBR, TS and surrounding waters. On December 12, 2015, warm water was present only in the far southern GC. On December 26,2015 , warm water $\left(>30^{\circ} \mathrm{C}\right)$ had occurred in both the southern and northern regions of the GC. By January 9, 2016, warm water had spread in the northern and southern TS and over coastal waters of the GP, and Princess Charlotte Bay was also heating in isolation. By January 23, the GC was measurably heated and a warm water plume occurred from the southern TS into the far northern region of the NGBR. This warm water plume tongue grew southward and covered much of the NGBR by February 6, 2016. By February 20, 2016, this water had become even warmer, reaching $32^{\circ} \mathrm{C}$ in the central region of the NGBR. On February 27 the temperature in most of the far-northern NGBR and the whole of TS exceeded $30{ }^{\circ} \mathrm{C}$, with patches reaching and sometimes exceeding $32{ }^{\circ} \mathrm{C}$. Throughout March the SST data was very patchy. For instance in SST image for March 19, 2016 (Figure 2h) 
195

206

207

208

209

there are very few pixels in the northern NGBR and in TS, meaning there was little data available there, likely due to cloud cover. On April 2, 2016, the temperature in most of the NGBR and TS waters was $>30^{\circ} \mathrm{C}$, with small patches at $32{ }^{\circ} \mathrm{C}$. The SST was measurably cooler by April 9 , 2016 and the temperature in most of the NGBR and the southern TS was at $28{ }^{\circ} \mathrm{C}$ by April 16 , 2016, though the far northern TS and the GC still remained warm $\left(\sim 30^{\circ} \mathrm{C}\right)$.

It is only by the end of February 2016 that warm water pools occurred in the NCS, but there is no evidence of this warm water intruding in the NGBR or TS. Instead there seems to exist a thin layer of cooler water along the outer NGBR shelf separating these waters.

Figure 2 also shows cooler water patches along the shelf break.

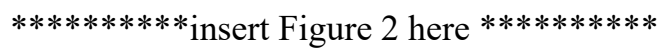

Figure 3 shows sequential plots of the altimetry-derived geostrophic surface currents in the GP and the NCS. Altimetry measured a net eastward flow through TS from December 2015 to March 2016, however the strength of these currents was likely to have been greatly overestimated because these data neglect the high friction in shallow waters. There was no NQCC in December 2015; it reformed and was very weak (speed $<0.1 \mathrm{~m} \mathrm{~s}^{-1}$ ) in January and February 2016 and it disappeared again in March and reformed in April 2016. From January to March 2016, there was a counter-clockwise circulation in the northern NCS and the GP, as well as a southward flow in the NCS along the shelf break of the NGBR.

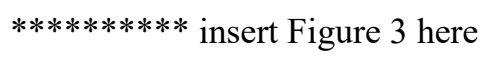

Figure 4 shows the predicted fate from November 2015 to February 2016 of virtual particles released in the NCS along the shelf break of the NGBR, using the NCS oceanographic model based on altimetry current data. The particles were initially exported seaward south-eastward, then advected 
northeastward across the NCS, and finally they moved southwestward across the NCS again to return

211 near the original seeding sites after four months.

212

$* * * * * * * * *$ insert Figure 4 here

214 small, generally $<8 \mathrm{~m} \mathrm{~s}^{-1}$ (Figure 5). This general pattern prevailed from December 2015 to March 2016 (not shown). The wind generated a MSL difference across TS of up to $0.4 \mathrm{~m}$, the western side (GC) being higher than the eastern side (GP and NCS), and the MSL difference increased with increasing wind speed and vanished during calm weather (Figure 5).

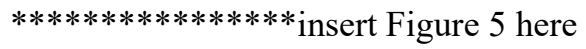

Figure 6 shows the predicted trajectories over 20 days of virtual Lagrangian particles seeded in the TS domain on February 1, 2016, using the SLIM model. The particles moved eastward from the GP into TS after 5 days. After crossing the passages in the western TS, some of these particles, as well as the particles seeded in TS itself, moved northeastward while the majority of the particles moved southward into the NGBR on the inner shelf. The flow took approximately three weeks to flow through TS and enter the NGBR, during which time a large dispersion occurred.

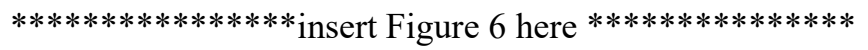

Figure 7 shows the predicted trajectories over 45 days in February-March 2016 of virtual warm water Lagrangian particles seeded on the inner shelf of the northern NGBR domain on February 1, 2016, following the predictions (Figure 6) of the intrusion zone of the warm water plume from the GC. The warm water particles moved southward longshore but did not reach Princess Charlotte Bay. Instead the majority progressively dispersed cross-shelf; on reaching the outer shelf they were rapidly (in a few days) flushed into the NCS by the strong tidal currents in that area due to the tidal jets 
238 forming in reef passages. About $30 \%$ of the particles were trapped in the mid-shelf reef mosaic and in

239 shallow, coastal embayments.

\section{Conclusions}

The satellite-measured SST show that the 2016 ENSO heating started in the Gulf of

Strait (TS) through passages at its southern side and then slowly spread both southward on the inner shelf into the Northern Great Barrier Reef (NGBR) and also northward towards the northern TS. This is supported by the wind data (Figure 5), which show consistent westerly winds in TS during this period. An extremely warm water $\left(\sim 32{ }^{\circ} \mathrm{C}\right)$ pool formed on the inner and mid-shelf of the NGBR, in an area of high reef density. The NCS also heated, but much less and a thin streak of colder water occurred all along the reefs at the shelf break. We suspect this cold water streak was due to vertical mixing of deep, cold oceanic water upwelled by tidal jets in reef passages [Thomson and Wolanski, 1984; Wolanski et al., 1988].

Altimetry-derived surface currents suggest that the North Queensland Coastal Current, which would normally flush and cool the NCS and, by tidal mixing, the outer shelf of the NGBR, actually did the opposite, namely it reversed sign and brought warm water from the TS and the Gulf of Papua

257 (GP) to the NCS along the NGBR. A simple 2D advection-diffusion model based on these observed currents suggest that a counter-clockwise circulation occurred in the NCS and the GP during this ENSO event and that this trapped warm water in the NCS.

Oceanographic modeling using the tides, the local wind and the satellite-derived mean sea level difference across Torres Strait reproduced qualitatively well the observations of GC warm water plume intrusion in the TS, and suggest the likely mechanism: consistent westerly winds set up a mean sea level gradient across TS (Figure 5), which in turn set up a net eastward current through TS, transporting the warm water plume from GC across TS and into the northern NGBR (Figure 6). The 
modelling also shows that this plume split into a plume moving northward on the outer shelf towards the northeast region of TS and another plume moving southward in the NGBR on the inner shelf. On reaching the southern third of the NGBR, the plume mixed cross-shelf. On reaching the outer shelf the warm water was rapidly (in a few days) flushed into the NCS by the strong tidal currents in that area due to the tidal jets forming in reef passages. About $30 \%$ of the particles were trapped in the mid-shelf reef mosaic as a result of the sticky water effect [Andutta et al., 2012] and in shallow, coastal embayments. The location of this predicted stagnation area (Figure 7) corresponds qualitatively well with the SST data in the NGBR (Figure 2). Similarly the model reproduced qualitatively well the observations from the SST data that the very warm water plumes were largely restricted to the inner and mid-shelf.

Figure 8 shows the map of bleaching intensity of coral reefs in the NGBR. It shows smaller bleaching on the outer shelf than on the inner and mid-shelf. Because bleaching is a function of both the temperature and the residence time of that warm water over the coral reefs, our oceanographic findings that the residence time of warm water was smaller offshore than inshore qualitatively explains the bleaching map. The large patch of not-bleached corals on the mid-shelf in the NCS just south of Torres Strait may be explained by the modeling predictions that the intrusive GC warm water plume was confined to the inner shelf in this area of the NGBR.

\section{$* * * * * * * * * * *$ insert Figure 8 here $* * * * * * * * *$}

It should be noted that this study is to some extent subjective due to the lack of oceanographic field data available for the 2016 ENSO event for verifying the models. What we presented is our best-informed attempt to reveal the mechanisms involved in causing the event, based on the available data combined with existing body of knowledge of the water circulation in and around the TS/NGBR region. The models employed here have previously been used extensively to study water flow in the region, and are forced and calibrated with real oceanographic data at the open boundaries. Likewise, the lack of oceanographic dispersion data means it is not possible to derive a precise value for the horizontal eddy diffusivity parameter $\mathrm{K}_{\mathrm{x}}$, so the value used was estimated to be 
$10 \mathrm{~m}^{2} \mathrm{~s}^{-1}$ from Wolanski and Elliott (2015). A smaller (larger) value of $\mathrm{K}_{\mathrm{x}}$ would result in smaller (higher) dilution of the warm water plume. Also, we have no data on the vertical temperature profiles during this heating event. Finally, we do not propose a heat budget to quantify how much of the heating was due to local heating and how much was due to oceanographic advection of warm water from GC - however the SST data strongly suggest that this latter process played at least a significant contributory role in the 2016 ENSO event.

\section{Acknowledgments}

For readers interested to access the data, the contact person is Eric Wolanski (Email:

eric.wolanski@jcu.edu.au).

\section{References}

Ainsworth, T.D., S.F. Heron, J.C. Ortiz, P.J., Mumby, A. Grech, D., Ogawa, C.M, Eakin and W. Leggat, (2016). Climate change disables coral bleaching protection on the Great Barrier Reef. Science, 352, 338-342.

Andrews, J.C. and S., Clegg, (1989). Coral Sea circulation deduced from modal information models. Deep Sea Research, 36, 957-974.

Andutta, F., M., Kingsford, M., and E. Wolanski, (2012). 'Sticky water' enables the retention of larvae in a reef mosaic. Estuarine, Coastal and Shelf Science, 101, 54-63.

Andutta, F., P.V. Ridd, P.V. and E. Wolanski, (2013). The age and the flushing time of the Great Barrier Reef waters. Continental Shelf Research, 53, 11-19.

Brodie, J. and J. Waterhouse, (2012). A critical assessment of environmental management of the 'not so Great' Barrier Reef. Estuarine, Coastal and Shelf Science, 104-105, 1-22.

Brodie, J. and R.G. Pearson, (2016). Ecosystem health of the Great Barrier Reef: Time for effective management action based on evidence. Estuarine, Coastal and Shelf Science, 183, 438-451. 
Brodie, J., K. Fabricius, G., De'ath and K. Okaji, K., (2005). Are increased nutrient inputs responsible for more outbreaks of crown-of-thorns starfish? An appraisal of the evidence. Marine Pollution Bulletin, 51, 266-278.

Brodie, J.E., F.J., Kroon, B., Schaffelke, E., Wolanski, S., Lewis, M.J. Devlin, I. Bohnet, Z.T. Bainbridge, J. Waterhouse and A.M. Davis, (2012). Terrestrial pollutant runoff to the Great Barrier Reef: an update of issues, priorities and management responses. Marine Pollution Bulletin, 65, 81-100.

Brown, B. E., (1997). Coral bleaching: causes and consequences. Coral Reefs, 16, 129-138.

Cahill, M.L. and J.H. Middleton, (1993). Wind-forced motion on the northern Great Barrier Reef. Journal of Physical Oceanography, 23, 1176-1191

Douglas, A.E. (2003). Coral bleaching — how and why? Marine Pollution Bulletin, 46, 385-392.

Fabricius, K.E., K. Okaji, G., De'ath, (2010). Three lines of evidence to link outbreaks of the crownof-thorns seastar Acanthaster planci to the release of larval food limitation. Coral Reefs, 29 (3), 593-605.

Fabricius, K.E., C. Langdon, S., Uthicke, C., Humphrey, S., Noonan, G., De’ath, R., Okazaki, N., Muehllehner, M.S. Glas and J.M. Lough, (2011). Losers and winners in coral reefs acclimatized to elevated carbon dioxide concentrations. Nature Climate Change, 1, 165-169.

Fabricius, K.E., M. Logan, S.J. Weeks, S.E., Lewis and J. Brodie, (2016). Changes in water clarity related to river discharges on the Great Barrier Reef continental shelf: 2002-2013. Estuarine, Coastal and Shelf Science, 173, A1-A15.

Golbuu, Y., M. Gouezo, H., Kurihara, L., Rehm and E. Wolanski, (2016). Long-term isolation and local adaptation in Palau's Nikko Bay help corals thrive in acidic waters. Coral Reefs, 35, 909. doi:10.1007/s00338-016-1457-5

Hoegh-Guldberg, O., P.J. Mumby, A.J. Hooten, R.S. Steneck, P. E., C.D. Harvell, P.F. Sale, A.J. Edwards, K. Caldeira, N. Knowlton, C.M. Eakin, R. Iglesias-Prieto, N., Muthiga, R.H. Bradbury, A. Dubi and M.E. Hatziolos, (2007). Coral reefs under rapid climate change and ocean acidification. Science, 318, 1737-1742. 
Hughes, M.G., P.T. Harris, A. Heap and M.A. Hemer, (2008). Form drag is a major component of bed shear stress associated with tidal flow in the vicinity of an isolated sand bank, Torres Strait, northern Australia. Continental Shelf Research, 28, 2203-2213.

Jackson, J.B.C., M.X. Kirby, W.H. Berger, K.A. Bjorndal, L.V. Botsford, B.J. Bourque, R.H. Bradbury, R. Cooke, J. Erlandson, J.A. Estes, T.P. Hughes, S. Kidwell, C.B. Lange, H.S. Lenihan, J.M. Pandolfi, C.H. Peterson, R.S. Steneck, M.J. Tegner and R.R. Warner, (2001). Historical overfishing and the recent collapse of coastal ecosystems. Science, 293,629-638.

Krishna Rao, P.., W.L. Smith and R. Koffler, (1972). Global Sea-Surface Temperature Distribution Determined from an Environmental Satellite. Monthly Weather Review, 10, 10-14.

Lambrechts, J., E. Hanert, E., Deleersnijder, P.-E. Bernard, V. Legat, J.-F. Remacle and E. Wolanski, (2008). A multi-scale model of the hydrodynamics of the whole Great Barrier Reef. Estuarine, Coastal and Shelf Science 79, 143-151.

Legrand, S., E. Deleersnijder, E. Hanert, V. Legat and E. Wolanski, (2006). High-resolution, unstructured meshes for hydrodynamic models of the Great Barrier Reef, Australia. Estuarine, Coastal and Shelf Science 68, 36-46.

Manzello, D. P. (2015). Rapid recent warming of coral reefs in the Florida Keys. Nature Scientific Reports, 5, 16762, doi: 10.1038/srep16762.

Mongin, M., M.E. Baird, B. Tilbrook, R.J. Matear, A. Lenton, M. Herzfeld, K. Wild-Allen, J. Skerratt, N. Margvelashvili, B.J. Robson, C.M. Duarte, M.S.M. Gustafsson, P.J. Ralph and A.D.L. Steven, (2016). The exposure of the Great Barrier Reef to ocean acidification. Nature Communications, 7: 10732.

Oliveira, P.B. and Y. Stratoudakis, (2008). Satellite-derived conditions and advection patterns off Iberia and NW Africa: potential implications to sardine recruitment dynamics and population structuring. Remote Sensing Environment, 112, 3376-3387.

Pickard, G.L., J.R. Donguy, C. Henin and F. Rougerie, (1977). A review of the physical oceanography of the Great Barrier Reef and western Coral Sea. Australian Institute of Marine Sciences, Monography Series vol. 2 Australian Government Printer, Canberra. 


\section{9}

Precht, W. F., B.E. Gintert, M.L. Robbart, R. Fura and R. van Woesik, (2016). Unprecedented disease-related coral mortality in Southeastern Florida. Nature Scientific Reports, 6, 31374; doi: $10.1038 /$ srep31374.

Thomson, R.E. and E. Wolanski, (1984). Tidal period upwelling within Raine Island Entrance, Great Barrier Reef. Journal of Marine Research, 42, 787-808.

Wolanski, E., (1993). Water circulation in the Gulf of Carpentaria. Journal of Marine Systems, 4, 401420.

Wolanski, E., (1994). Physical oceanography processes of the Great Barrier Reef. CRC Press, Boca Raton, Florida, 194 pp.

Wolanski, E. and B. Ruddick, (1981). Water Circulation and Shelf Waves in the Northern Great Barrier Reef Lagoon. Australian Journal Marine Freshwater Research, 32, 721-740.

Wolanski, E., G.L. Pickard, and D.L.B. Jupp, (1984). River plumes, coral reefs and mixing in the Gulf of Papua and the northern Great Barrier Reef. Estuarine Coastal and Shelf Science, 18, 291-314.

Wolanski, E. and R.E. Thomson, (1984). Wind-driven circulation on the northern Great Barrier Reef continental shelf in summer. Estuarine, Coastal and Shelf Science, 18,271-289.

Wolanski, E., E. Drew, K. Abel, K. and J. O’Brien, (1988). Tidal jets, nutrient upwelling and their influence on the productivity of the algal Halimeda in the Ribbon Reefs, Great Barrier Reef. Estuarine, Coastal and Shelf Science, 26, 169-201.

Wolanski, E., A. Norro and B. King, (1995). Water circulation in the Gulf of Papua. Continental Shelf Research, 15, 185-212.

Wolanski, E. and M. Elliott, (2015). Estuarine Ecohydrology. An Introduction. Elsevier, Amsterdam. $322 \mathrm{pp}$.

Wolanski, E., (2016). Bounded and unbounded boundaries - Untangling mechanisms for estuarinemarine ecological connectivity: Scales of $\mathrm{m}$ to $10,000 \mathrm{~km}$ - A review. Estuarine, Coastal and Shelf Science, http://dx.doi.org/10.1016/j.ecss.2016.06.022. 
Figure 1: (a) General location map showing the Gulf of Carpentaria (GC), Torres Strait (TS), Northern Great Barrier Reef (NGBR), Northern Coral Sea (NCS), Gulf of Papua (GP), Queensland (QLD), Papua New Guinea (PNG) and the North Queensland Coastal Current (NQCC), and the TS and NGBR model domains. (b) Zoom-in of the southern region of the TS domain, showing the mesh and the bathymetry (depth in in $\mathrm{m}$ ). (c) The NGBR model domain showing the mesh and the bathymetry (depth in $\mathrm{m}$ ). The thick black arrow in (c) points to the shallow, narrow channel connecting the NGBR with the remaining Great Barrier Reef further south. PCB=Princess Charlotte Bay.

Figure 2: Observed SST between December-2015 and March 2016 (source: 412 https://help.aodn.org.au/satellite-data/product-information/). (a) December 12, 2015; (b) December 26, 2015; (c) January 9, 2016; (d) January 23, 2016; (e) February 6, 2016; (f) February 20, 2016; (g) February 27, 2016; (h) March 19, 2016; (i) April 2, 2016; (j) April 9, 2016; (k) April 16, 2016.

Figure 3: Altimetry-derived, 5-days averaged, surface currents in the NCS on (a) December 15, 2015, (b) January 15, 2016, (c) February 15, 2016, (d) March 15, 2015 and (d) April 15, 2015 and (e) April 30, 2016. TS=Torres Strait, PNG=Papua New Guinea, GP=Gulf of Papua, NCS=Northern Coral Sea.

Figure 4: Using the altimetry-derived currents, snapshots of the predicted particle plume in the 421 Northern Coral Sea (NCS) and the Gulf of Papua (GP) on (a) November 20, 2015 (this shows the 422 assumed seeding sources in the NCS at the continental shelf break of the NGBR), (b) December 20, 2015, (c) January 20, 2016 and (c) February 20, 2016. The arrows indicate the general movement of the particles. The colour bar shows the number of particles per cell.

Figure 5: Time-series plot in February 2016 of (a) the altimetry-measured Mean Sea Level (MSL) east (E) and west (W) of Torres Strait and (b) the daily-averaged wind at Coconut Island. 
428 Figure 6: SLIM-model predictions of the plumes of virtual warm water particles at midnight on (A)

429 February 1, 2016, (B) February 5, (c) February 10, and (d) February 20. The particles were released at $4300 \mathrm{~h}$ on February 1. The colour bar shows the depth (in $\mathrm{m}$ ).

431 Figure 7: SLIM-model predictions of the plumes of virtual warm water particles on (A) February 1, 4322016 (24 hours after their release in the far northern NGBR), and (B-F) after 10, 20, 30, 40 and 45 433 days, respectively. PCB=Princess Charlotte Bay. The colour bar shows the depth (in m).

434 Figure 8: A map of the bleached status of coral reefs in the northern GBR following the 2016 ENSO 435 event (source: Michael Bode, pers. com.). 
Figure 1. 


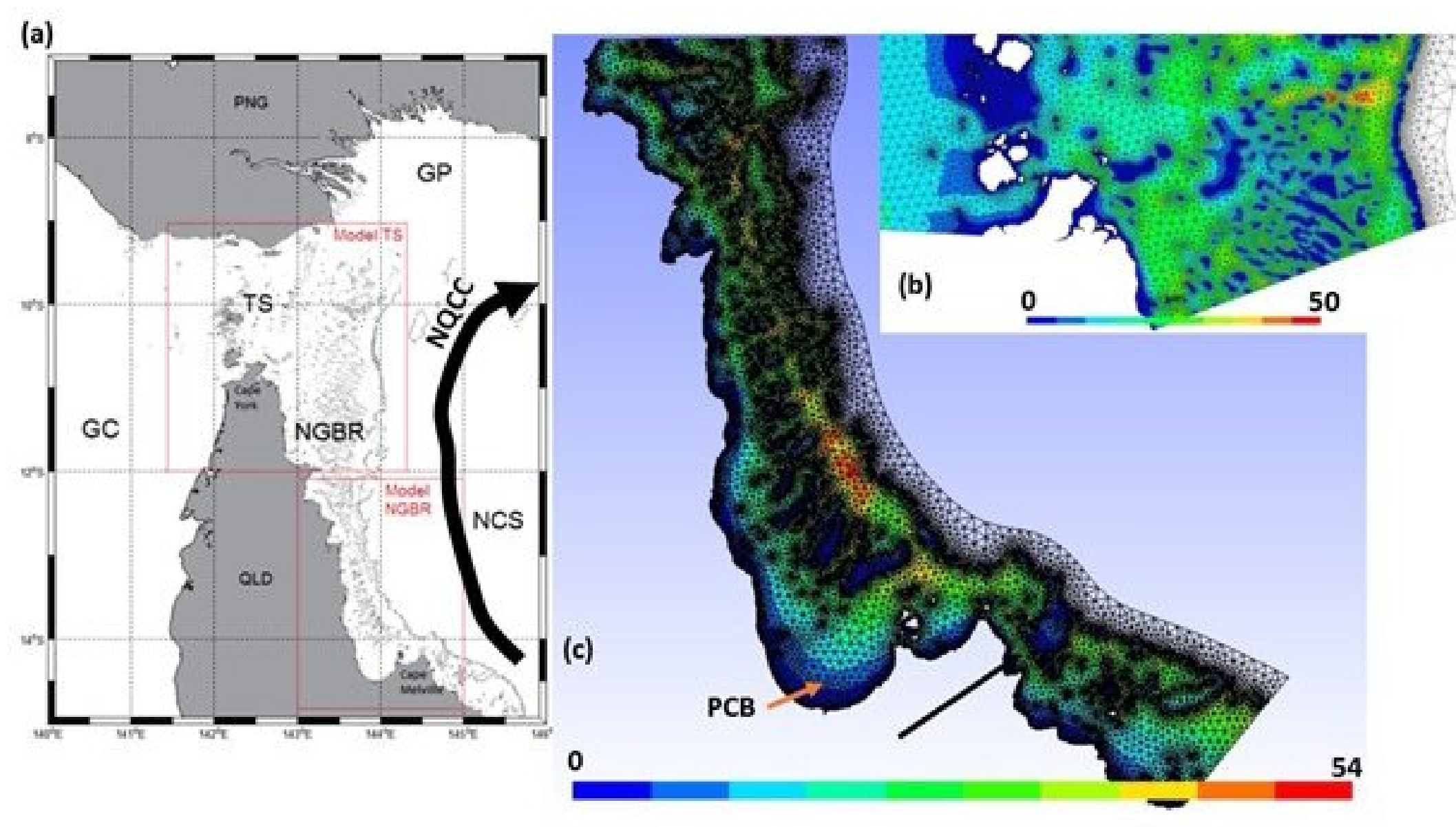


Figure 2. 


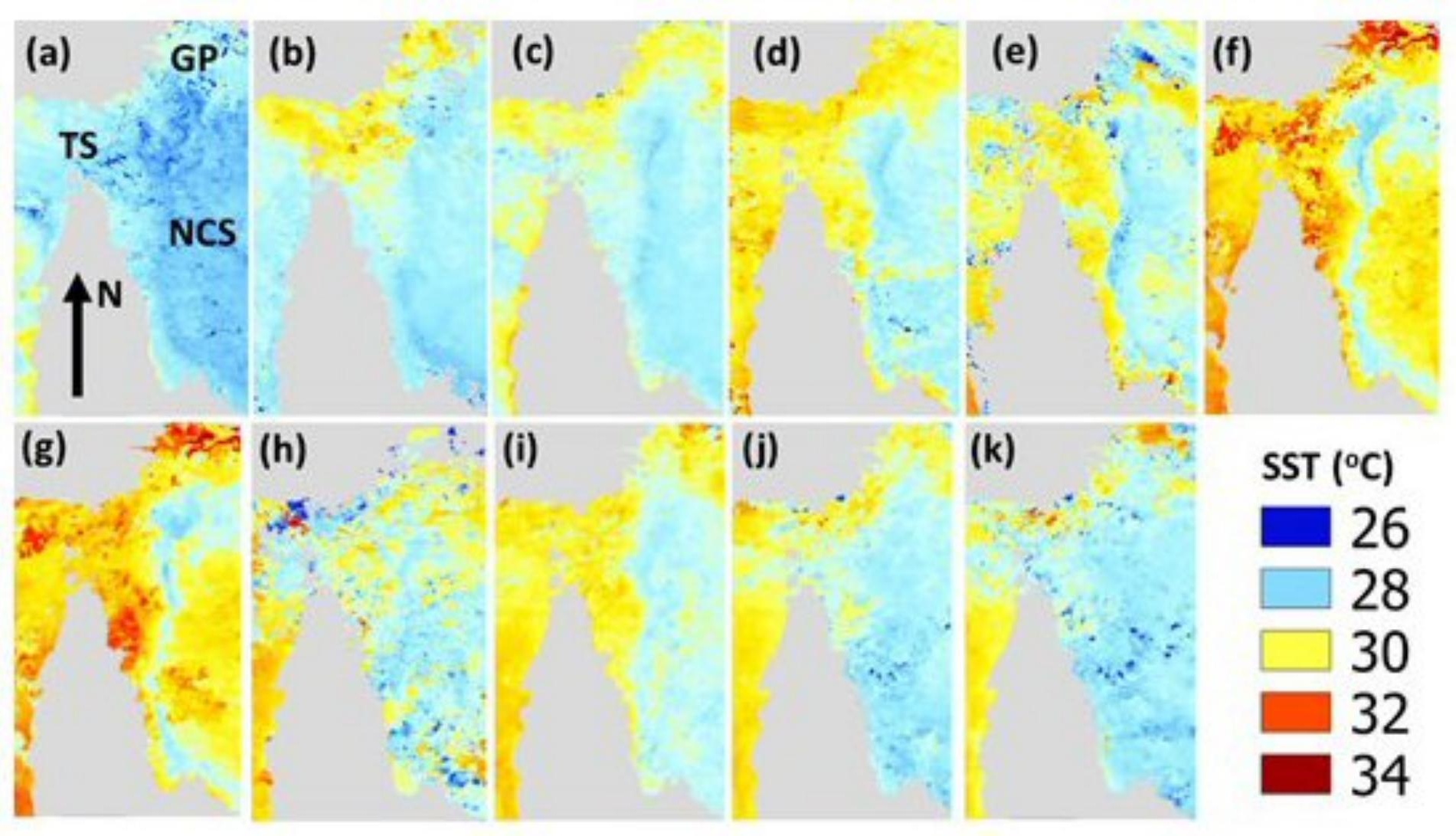


Figure 3. 


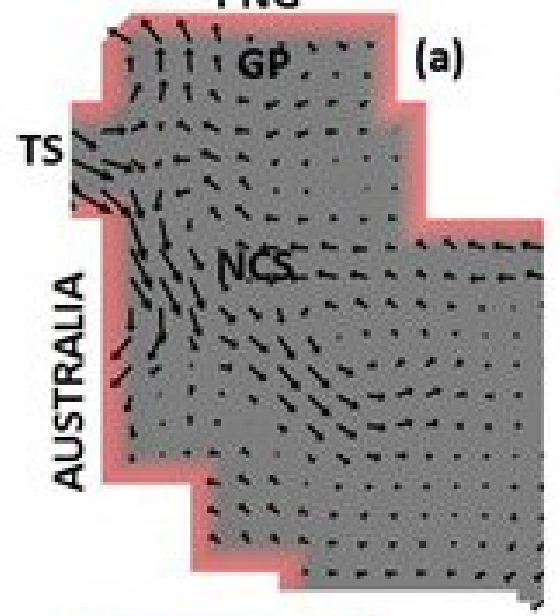

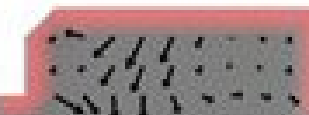

(d)

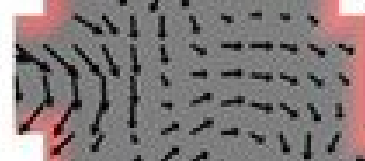

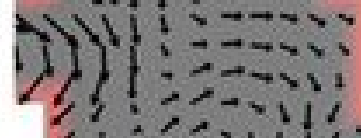

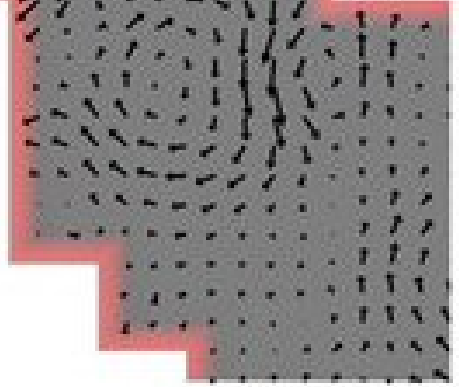

(b)

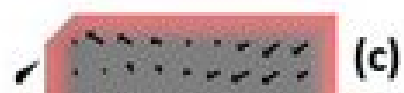

(c)

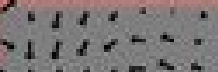

$\rightarrow 1+11<+\cdots+\cdots$

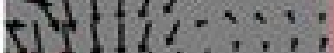

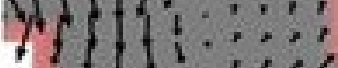

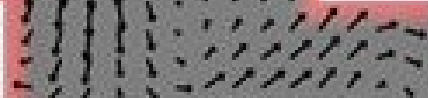

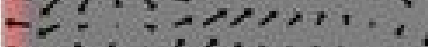

-

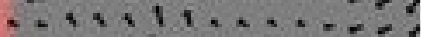

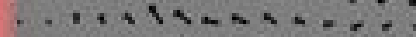

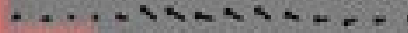

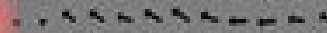

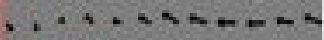

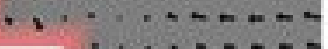

$x^{*}+,=-2=$

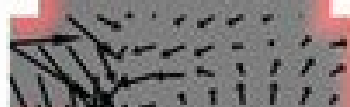

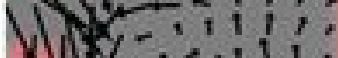

I.

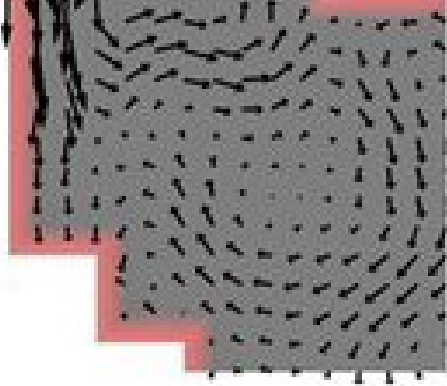

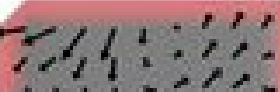

(e)

$v^{3}+1+2,-2$

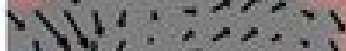

1)

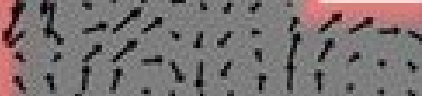

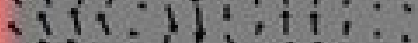

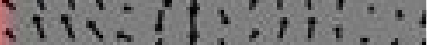

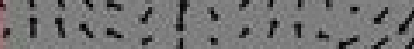

$\uparrow^{N}{ }_{1 m s}$ 
Figure 4. 


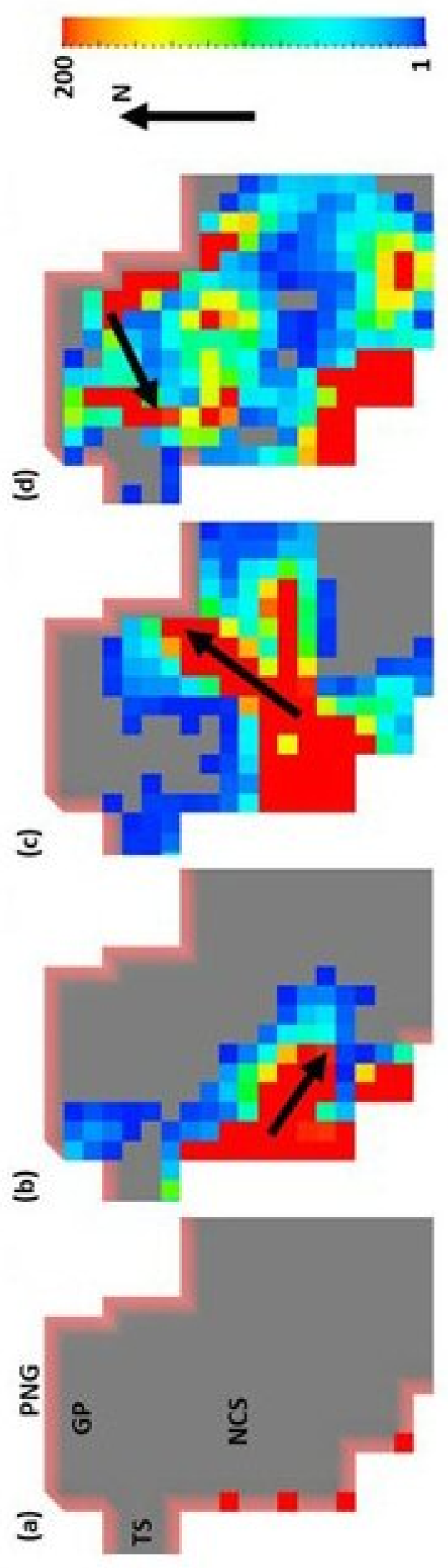


Figure 5. 


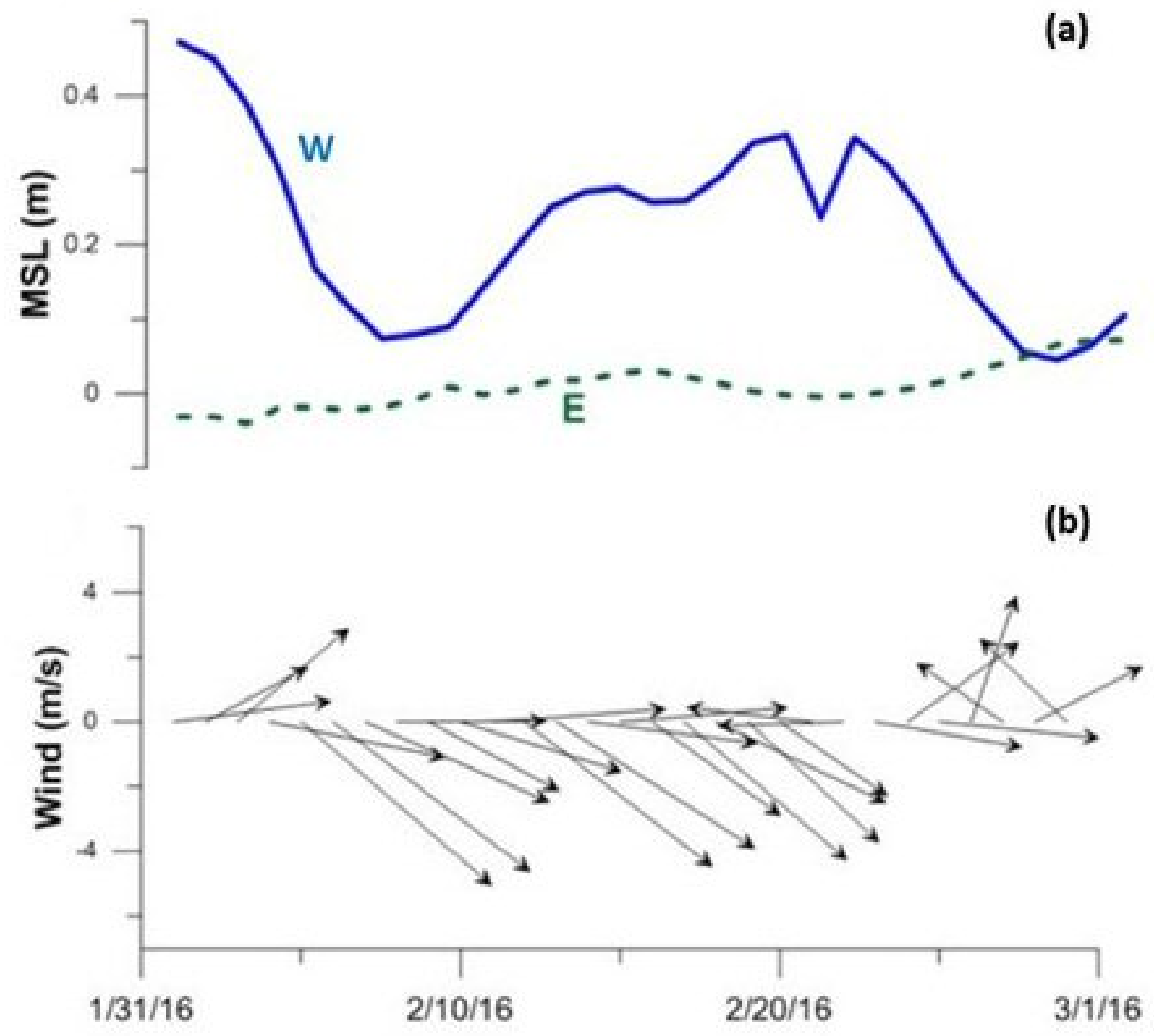


Figure 6. 
A)

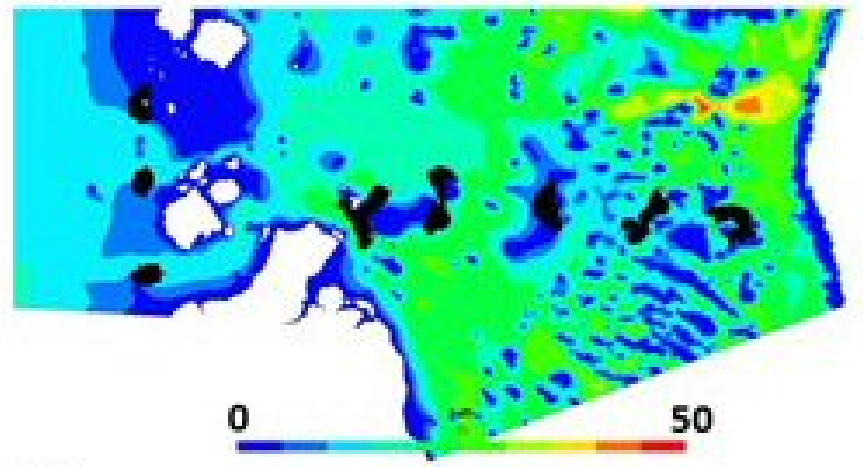

C)

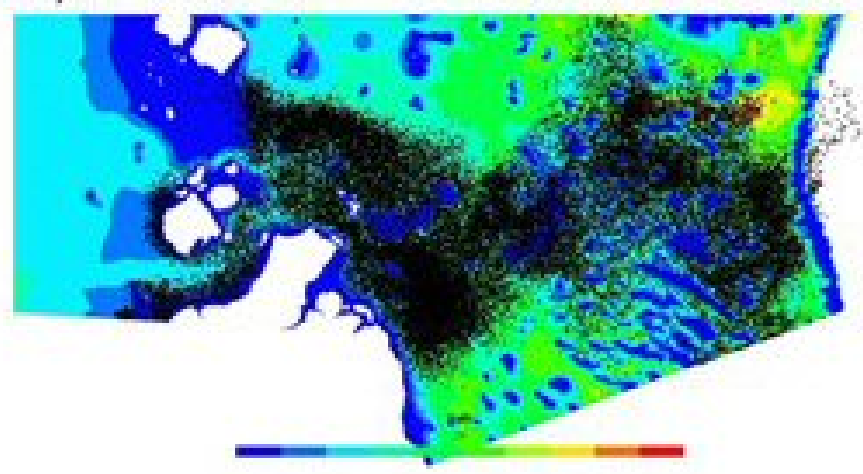

B)

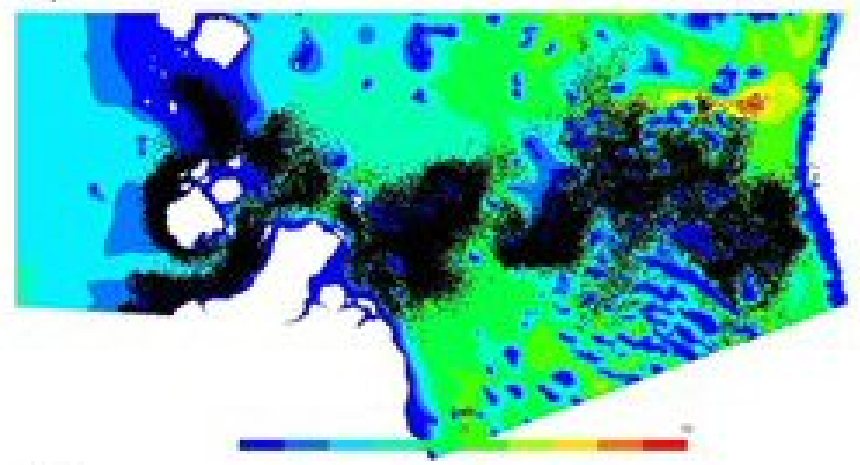

D)

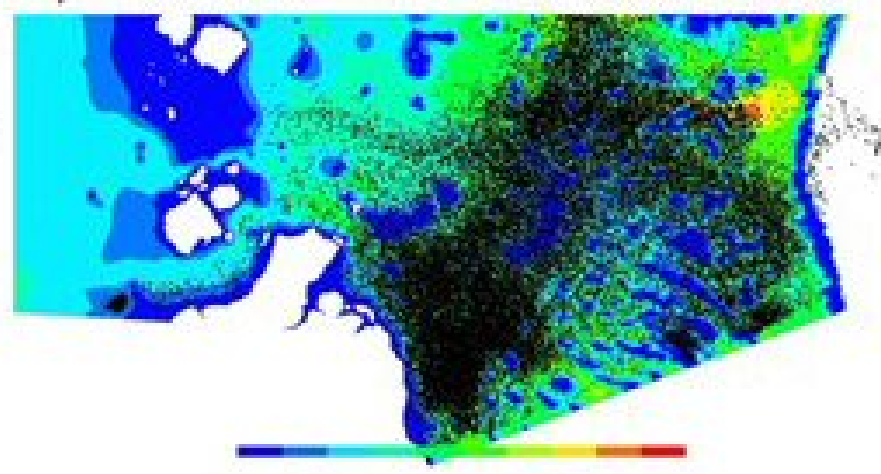


Figure 7. 
B)

C)

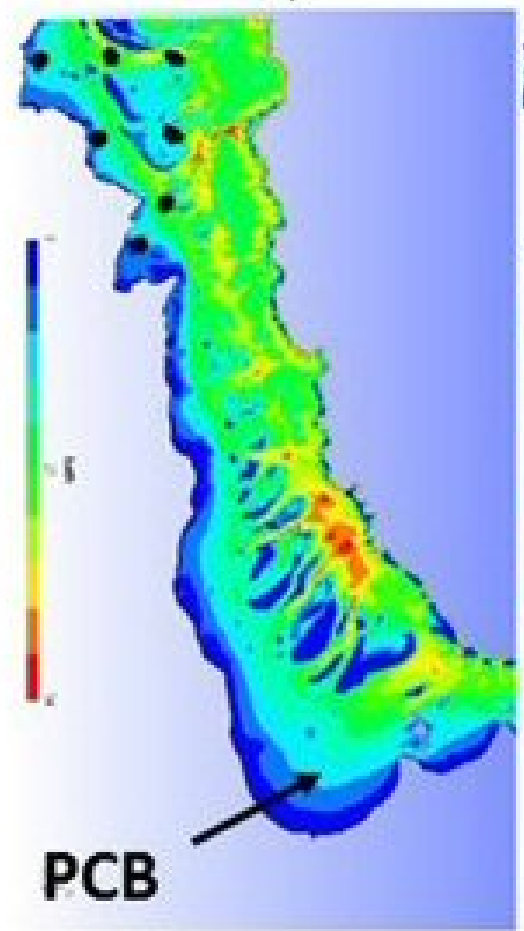

D)
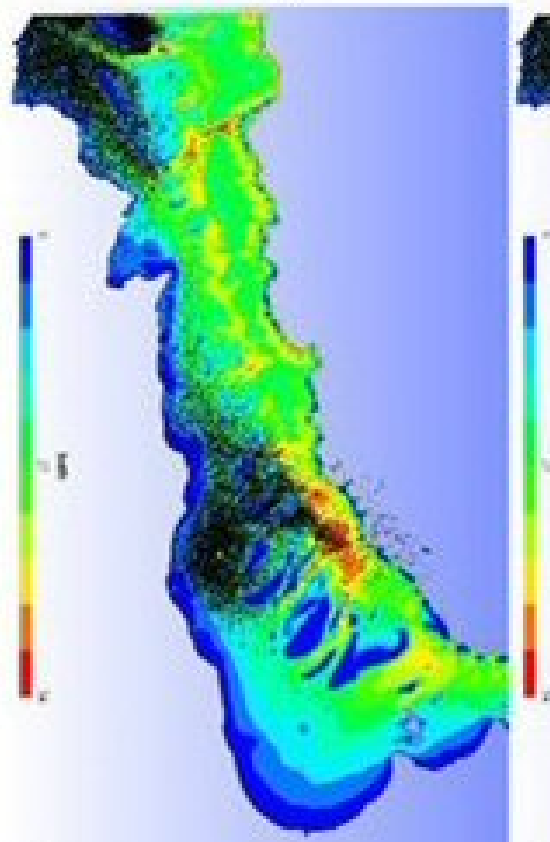

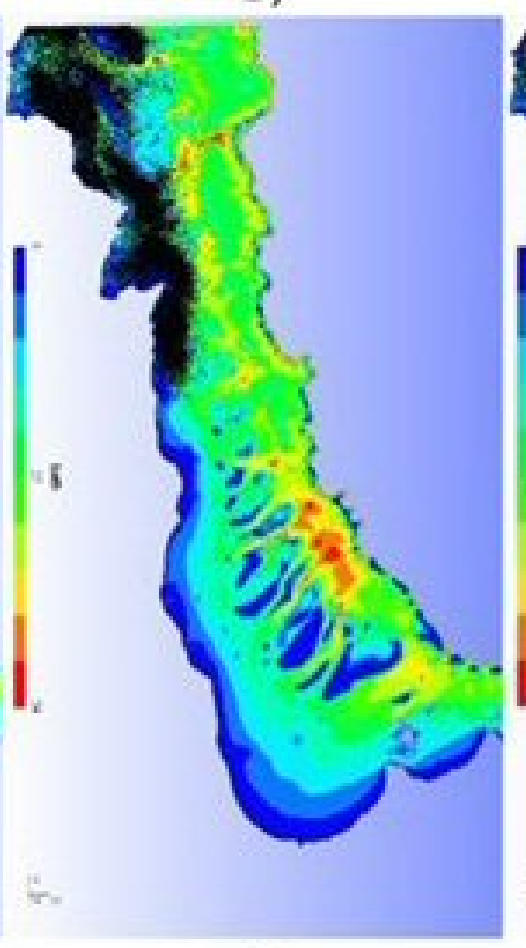

E)
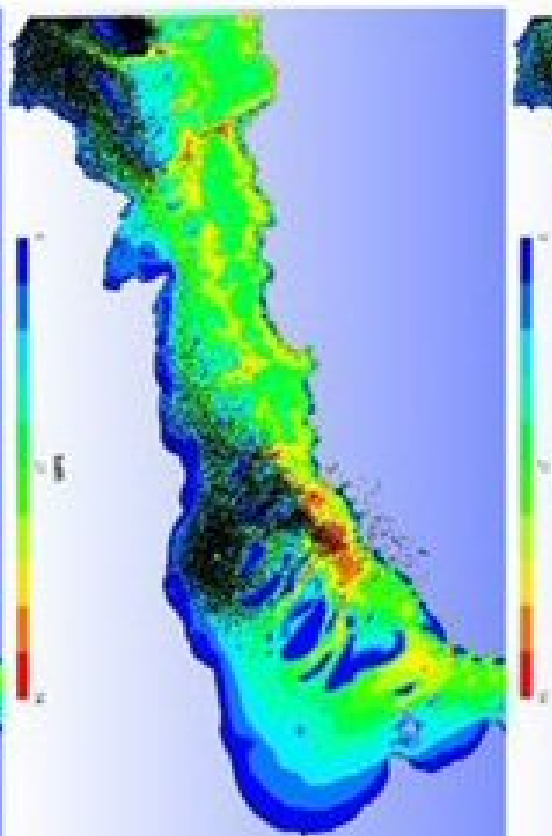

\section{F)}
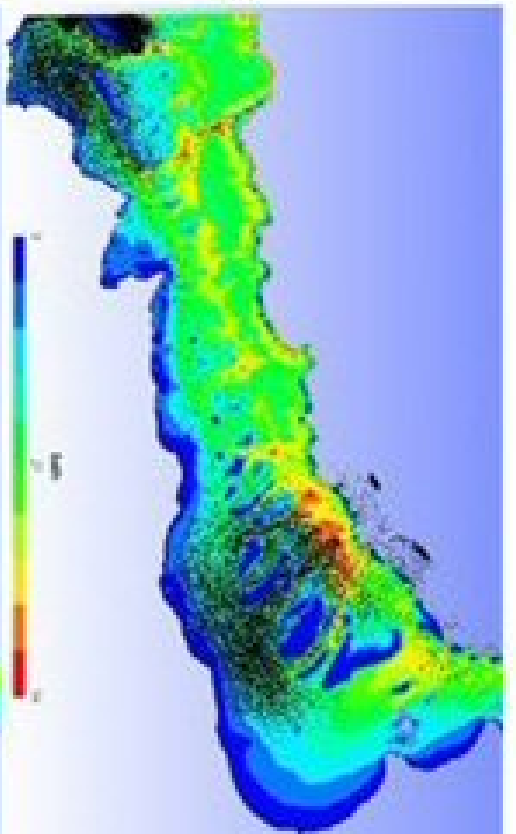
Figure 8. 


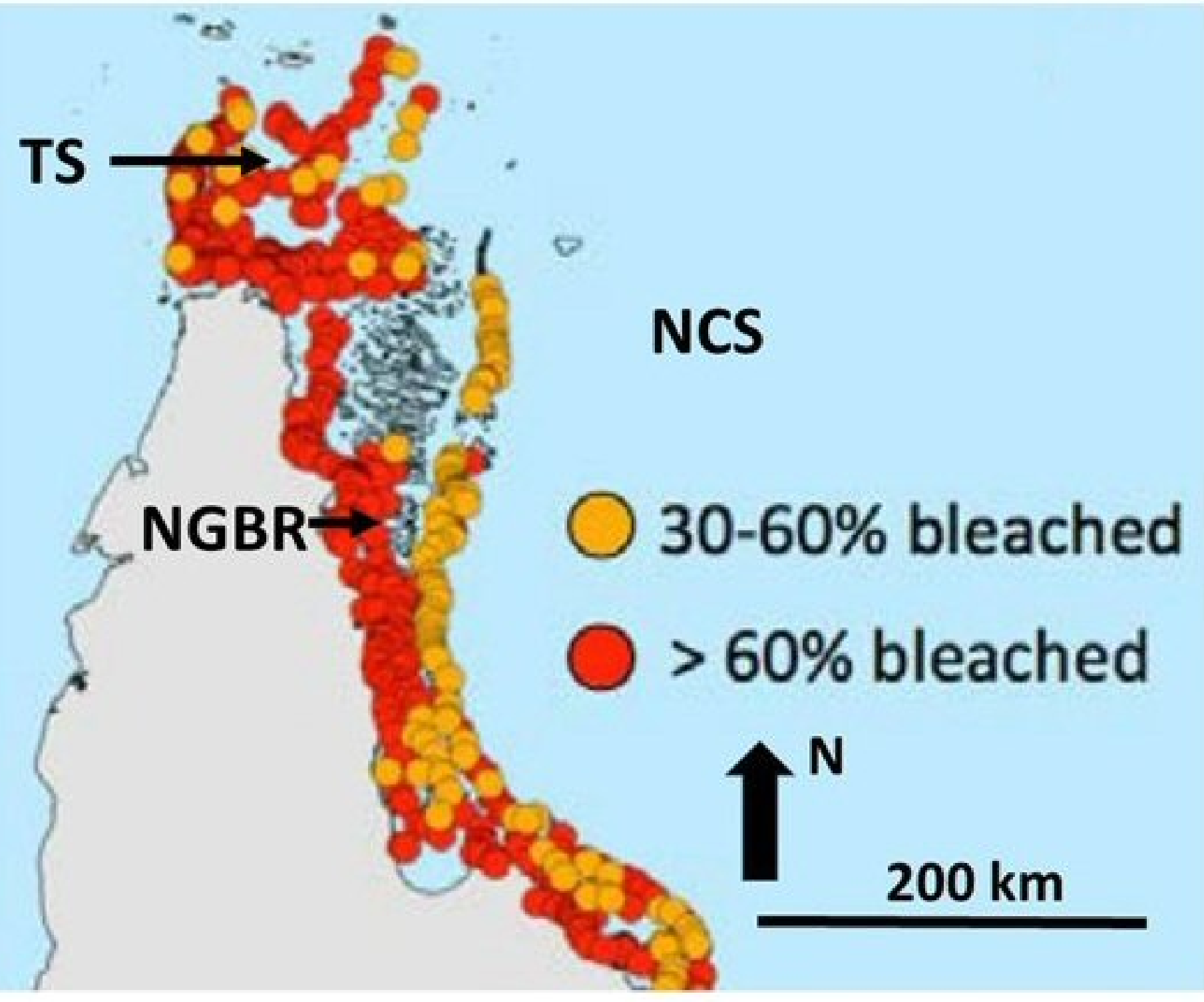

